\title{
REGIME ALIMENTAR DE GIRINOS DE RÃ TOURO
}

\author{
José TeIXEIRA De SEIXAS Filho ${ }^{1}$, Rodrigo Diana NAVARro ${ }^{2}$, SILVANa LAGES RIBEIRo Garcia ${ }^{3}$, \\ ANA CAROLINA DA SILVA SANTOS ${ }^{4}$ \\ ${ }^{1}$ Pesquisador Doutor do Fundação Instituto de Pesca do Estado do Rio de Janeiro - FIPERJ, Niteroi, RJ - Brasil \\ ${ }^{2}$ Professor de aquicultura da Universidade de Brasília, Brasília, DF, Brasil. navarrounb@ gmail.com \\ ${ }^{3}$ Professora Mestre do Instituto Viçosence de Ensino e Pesquisa, Faculdade de Viçosa - FDV, Viçosa, MG, Brasil. \\ ${ }^{4}$ Especialista pelo Centro Universitário Augusto Motta, Bonsucesso, RJ, Brasil
}

\begin{abstract}
Foram utilizados 525 girinos de rã-touro durante 60 dias, distribuídos em 15 caixas, com um girino por litro. A água foi renovada $200 \%$, a cada 24 horas. Os regimes alimentares foram elaborados por meio de cinco arranjos elaborados com sete rações comerciais com níveis de 22, 28, 32, 36, 40, 45 e 55\% de proteína bruta (PB), ministradas a cada 15 dias. Foi utilizado o delineamento em blocos ao acaso, em parcela subdividida, com três repetições. As subparcelas foram constituídas por cinco biometrias: na instalação do experimento, $15,30,45$ e 60 dias. Os girinos submetidos aos regimes alimentares RA1, com 22, 32,
\end{abstract}

36 , e $40 \%$ de PB, apresentaram o maior consumo e o mesmo desempenho dos demais. Já os que receberam o RA5, com 40, 45, 45 e 50\% de PB, apresentaram maior peso, mas o menor ganho de peso, maiores consumo, conversão e mortalidade, indicando que esses regimes oneram e não foram adequados ao manejo. Os regimes alimentares com 28, 32, 36 e $40 \%$ de PB e com 32, 36, 40 e $45 \%$ de $\mathrm{PB}$ foram mais adequados a esse tipo de manejo. Os animais, em todos os tratamentos, alcançaram desempenho maior que os alimentados tradicionalmente.

PALAVRAS-CHAVE: exigência nutricional; nutrição de rã; proteína.

FEEDING PROGRAMS FOR BULLFROG (Lithabates catesbeianus- Rana catesbeiana, Shaw 1802)

\section{ABSTRACT}

We used 525 bullfrog tadpoles, distributed into 15 boxes with one tadpole per liter. The water was daily renewal $(200 \%)$. The feeding regimes were constituted of five arrangements using seven commercial rations with levels of $22,28,32,36,40,45$ and $55 \%$ of crude protein (CP), supplied every 15 days. We used a random blocks design, subdivided plots with three replications. The subplots were constituted of five biometries: at the beginning of the experiment, at 15 , 30,45 , and 60 days. The tadpoles submitted to feeding regime FR1, with 22, 32, 36, and $40 \%$ of $\mathrm{CP}$, presented the highest consumption and the same performance as the others. Tadpoles that received FR5, with 40, 45, 45 and $50 \%$ of $\mathrm{CP}$, presented greater weight, however, they showed smaller weight gain, greater consumption, conversion and mortality, indicating that this regime is expensive and not adequate for management. Feeding regimes FR2, with $28,32,36$ and $40 \%$ of $\mathrm{CP}$, and FR3, with $32,36,40$ and $45 \%$ of $\mathrm{CP}$, were more adjusted to this kind of management. Animals in all treatments showed higher performance that animals fed traditionally.

KEYWORDS: bullfrog nutrition; nutritional requirement; protein. 


\section{INTRODUÇÃO}

$\mathrm{Na}$ criação de girinos, a fase aquática da ranicultura é a base para a obtenção de bom resultado do ranário (ALBINATI et al., 2000), onde se registram grandes perdas e, ou, baixo desempenho dos animais, geralmente, apresentando sinais prováveis de deficiências nutricionais (SEIXAS FILHO, 2011a; BARBOSA et al., 2005); associados à qualidade da água, conforme já relatado por FONTANELLO et al. (1982). Segundo CASTAGNOLLI (1992) e TAVAREZ (1994), a qualidade da água inclui todas as características físico-químico-biológicas que possam influir na sua utilização, sem interferência nos resultados de pesquisa.

LIMA \& AGOSTINHO (1992) relataram que o custo com a alimentação de rãs representa $57 \%$ do custo total da criação. SEIXAS FILHO et al. (2011a) comentaram que o principal problema para uma criação plena está relacionado à composição de um alimento nutricional adequado, principalmente quanto ao índice proteico, devido à falta de conhecimentos de suas exigências nutricionais.

No Brasil, principalmente, no Rio de Janeiro, o mercado para carne de rã ainda é pequeno, mas estabilizado, sendo que a totalidade dos ranicultores produz seus próprios girinos, utilizando rações comerciais para peixe, ao longo de todo o período larval, com um único nível de proteína, geralmente alto, aumentando os custos operacionais e piorando a qualidade da água (SEBRAE-RJ, 2002).

SEIXAS FILHO et al. (2011b) avaliaram o trato gastrintestinal de girinos da rã-touro e observaram que somente no $25^{\circ}$ dia após a alimentação exógena ocorreu a presença de células hepáticas com arranjo glandular mais compacto, sugerindo funcionalidade, o que permite inferir que a administração de ração com alto nível de nitrogênio, desde o início da criação, pode criar uma situação de toxidez no animal, por falta de condições fisiológicas para a sua metabolização, acarretando mortalidade, redução do crescimento e heterogeneidade da população.

HIPOLITO et al. (2001) afirmaram que todo o desempenho da rã-touro está baseado na alimentação e qualquer alteração na função hepática pode comprometer todo o aproveitamento proteico e nutricional. Nesse sentido, os mesmo autores, examinando fígado de rãs-touro alimentadas com rações comerciais, observaram, na sua grande maioria, vacuolização e rompimento do contorno celular, rarefação e degeneração celular hidrópica, quadro histopatológico associado à deficiência de proteína, podendo ser devido à má qualidade da proteína ou ao baixo aproveitamento pelo animal.

Pelo exposto, objetivou-se avaliar uma nova metodologia de alimentação dos girinos nessa fase da criação, testando-se regimes alimentares diferentes.

\section{MATERIAL E MÉTODOS}

O experimento foi conduzido no Laboratório de Pesquisas em Biologia da UNISUAM, - Rio de Janeiro - RJ.

Foram utilizados 525 girinos de rã-touro Lithabates catesbeianus, nova denominação da Rana catesbeiana (FROST et al., 2006), com 15 dias, no início da alimentação exógena, no estádio 25, segundo GOSNER (1960), durante o período experimental de 60 dias. Na alimentação dos girinos, foram utilizadas rações comerciais com sete níveis de proteína bruta (PB) - 22\%, 28\% $32 \%, 36 \%, 40 \%, 45 \%$, e $55 \%$ - (Tabela 1), com granulometria de $0,5 \mathrm{~mm}$, administradas na proporção de $10 \%$ do peso vivo dos girinos, distribuídas uma vez ao dia, às 12 horas, de acordo com SEIXAS FILHO et al. (2011b). Os animais foram distribuídos em 15 caixas plásticas com capacidade para 50 litros cada, com 35 litros, colocadas lado a lado em bancada, contendo no seu interior um cocho de PVC, onde se concentrava o alimento, e com densidade de um girino por litro de água, mantida durante todo o experimento, retirando-se um litro de água para cada animal morto (ARRUDA SOARES et al., 1983).

A renovação da água nas caixas, mantidas a uma temperatura constante de $25^{\circ} \mathrm{C}\left( \pm 1^{\circ} \mathrm{C}\right)$, foi, aproximadamente, de $200 \%$ do volume a cada 24 horas e foram escoadas por meio de canaletas de PVC acondicionadas lateralmente às bancadas e conectadas ao esgoto. O volume de água foi mantido por dispositivo tipo "joelho" adaptados às caixas de acordo com SEIXAS-FILHO et al. (1997).

Cada módulo experimental recebeu aeração constante, por meio de soprador e mangueiras plásticas $3 / 16^{\prime}$, providas de pedras porosas em suas extremidades e reguladas por registro de mesmo tamanho. 
Tabela 1 - Rações comerciais com 22\%, 28\%, 32\%, 36\%, 40\%, 45\% e 55\% de proteína bruta (PB) utilizadas na alimentação de girinos de rã-touro (Lithabates catesbeianu)

\begin{tabular}{lccccccc}
\hline Níveis de garantia & \multicolumn{7}{c}{ Ração (\% PB) } \\
& 22 & 28 & 32 & 36 & 40 & 45 & 55 \\
\hline Umidade máxima & 13,0 & 13,0 & 13,0 & 13,0 & 13,0 & 13,0 & 13,0 \\
Proteína bruta (PB) & 22,0 & 28,0 & 32,0 & 36,0 & 45,0 & 55,0 & 32,0 \\
Estrato etéreo (mínimo) & 4,0 & 4,0 & 7,0 & 8,0 & 8,0 & 10 & 7,0 \\
Matéria fibrosa (máximo) & 10,0 & 10,0 & 7,0 & 7,0 & 7,0 & 5,0 & 7,0 \\
Cinzas (máximo) & 14,0 & 14,0 & 2,6 & 3,1 & 3,1 & 3,0 & 2,6 \\
Cálcio - Ca (máximo) & 3,0 & 3,0 & 12,0 & 14,0 & 14,0 & 14,0 & 12,0 \\
Fósforo - P (mínimo) & 1,0 & 0,6 & 2,0 & 2,5 & 2,5 & 2,0 & 2,0 \\
\hline
\end{tabular}

Composição Básica

Farelo de soja, farinha de peixe, farelo de trigo, farelo de glúten de milho $60 \%$, farinha de carne e osso, milho, farinha de sangue, óleo de peixe, carbonato de cálcio, fosfato bicálcico, sal suplemento vit. ${ }^{1}$ e mineral ${ }^{2}$, antioxidante ${ }^{3}$.

${ }^{1}$ Composição por Kg: VIT. A - 12000 UI; VIT. D 3 - 4000 UI ; VIT. E - 150 UI ; VIT. K - 10 UI ; Ac. fólico - 10mg; Biotina - 0,8 $\mathrm{mg}$; Colina - $500 \mathrm{mg}$; Niacina - $150 \mathrm{mg}$; Pantotenato de cálcio - 50mg ; Tiamina - $30 \mathrm{mg}$; Riboflavina - $30 \mathrm{mg}$; Piridoxina B6 - 30

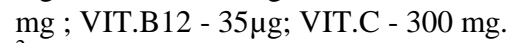

${ }^{2}$ Composição por Kg: Mg - 700 mg; Mn - 30 mg ; Zn - 200 mg ; Cu - 15 mg ; Fe - 100 mg ; I - 1 mg ; Se - 0,3 mg. .

${ }^{3}$ Etoxiquina - $250 \mathrm{mg}$.

$\mathrm{O}$ regime alimentar foi elaborado de forma a permitir a introdução, de maneira gradual, a cada quinze dias, de níveis crescentes de nitrogênio no metabolismo do animal, por meio de arranjo entre as sete rações comerciais (Tabela 2).

A ração foi fornecida aos girinos acondicionada em cochos que consistiam em tubos PVC de $50 \mathrm{~mm}$, cortados no sentido do comprimento, com extensão igual à largura da caixa. Os cochos foram fixados nas laterais do módulo experimental, para que permanecessem sem movimento (Figura 1).

Tabela 2 - Níveis de proteína bruta (\%) das rações comerciais ministrados nos diferentes regimes alimentares de girinos de rã-touro durante 60 dias

\begin{tabular}{cccccc}
\hline $\begin{array}{l}\text { Período } \\
\text { (dias) }\end{array}$ & RA1 & RA2 & RA3 & RA4 & RA5 \\
\hline & 22 & 28 & 32 & 36 & 40 \\
$15-15$ & 28 & 32 & 36 & 40 & 45 \\
$30-45$ & 32 & 36 & 40 & 45 & 45 \\
$45-60$ & 36 & 40 & 45 & 45 & 55 \\
\hline
\end{tabular}

${ }^{1}$ RA1 - 22, 28, 32 e 36\% de PB); RA2 - 28, 32, 36 e 40\% de PB; RA3 - 32, 36, 40 e 45\% de PB; RA4 - 36, 40, 45 e $45 \%$ de PB; RA5 - 40, 45, 45 e 55\% de PB ministrados a cada 15 dias.

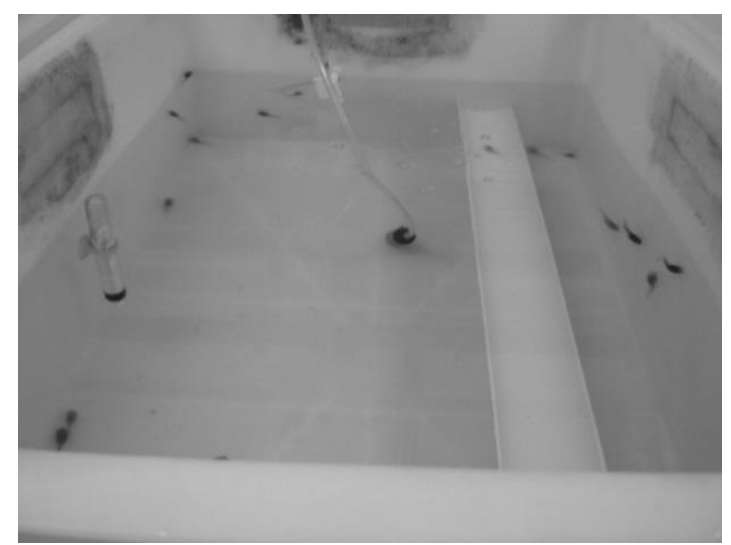

Figura 1 - Posicionamento do cocho de pvc para alimentação no módulo experimental para girinos de rã-touro (Lithabates catesbeianu)
A limpeza das caixas foi realizada todos os dias, por sifonagem de fundo, retirando-se as fezes e os restos alimentares. Diariamente, pela manhã e à tarde, foram medidos os valores de temperaturas do ar e da água por meio de termômetro de coluna de mercúrio, com escala em centígrados, de 0 a $60^{\circ} \mathrm{C}$. O controle da amônia e do $\mathrm{pH}$ foi efetuado diariamente, por meio de titulometria e de aparelho digital, respectivamente, a cada semana, com kit utilizado para controle de água de piscina.

As biometrias foram realizadas quinzenalmente, avaliando-se o peso, comprimento e sobrevivência. Os girinos foram colocados sobre toalha de pano umedecida, para retirada do excesso 
de água, sem que houvesse desidratação abrupta, e mensurados da boca até a inserção da cauda, com auxílio de paquímetro digital, com precisão de centésimos de milímetro. A seguir, cada animal foi transferido para recipiente plástico com volume de aproximadamente $5 \mathrm{~mL}$ de água e pesado em balança analítica, previamente tarada, com precisão de 0,001 g.

Para avaliação do consumo (CO), a sobra da ração administrada aos animais foi retirada dos cochos a cada 24 horas, por sifonagem, com auxílio de mangueira com diâmetro de 3/16' e filtragem, por meio de filtro com malha de $0,5 \mathrm{~mm}$, sem contaminação por fezes. As sobras foram secas em estufa ventilada a $55^{\circ} \mathrm{C}$, durante 24 horas. Após sua retirada da estufa, foram deixadas durante uma hora para entrar em equilíbrio com o meio ambiente e pesadas em balança digital com precisão de $0,001 \mathrm{~g}$. $\mathrm{O}$ consumo foi então obtido pela diferença entre a quantidade oferecida e a sobra de ração.

A conversão alimentar aparente (CAA) foi obtida pela razão entre o consumo de ração (CO) e o ganho de peso (GP). Por sua vez, o ganho de peso foi obtido pela diferença entre os pesos de duas biometrias consecutivas.

Foi utilizado o delineamento em blocos casualizados, no esquema em parcela subdividida, com três repetições. Nas parcelas foram testados os regimes alimentares (RA) (Tabela 1) e as subparcelas foram constituídas por cinco biometrias: na instalação do experimento (inicial) e aos 15, 30, 45 e 60 dias após a instalação. Os dados foram submetidos à análise de variância e teste F. Os regimes alimentares foram comparados por meio do teste de Newman-Keuls a 5\% de probabilidade.

\section{RESULTADOS E DISCUSSÃO}

A temperatura do ar apresentou média das mínimas e das máximas de 25 e $30^{\circ} \mathrm{C}$, respectivamente. A média da temperatura da água observada variou de 24 a $26^{\circ} \mathrm{C}$. O pH manteve-se na faixa de 7,0 a 8,9 e a amônia total foi de 0 a 0.25 e, quando comparada pela escala do kit para aquariofilia, manteve-se dentro do desejado. Os valores de temperatura e $\mathrm{pH}$ encontraram-se dentro dos limites aceitáveis para os girinos, sendo semelhantes aos das condições dos trabalhos de FONTANELLO et al. (1982) e SEIXAS-FILHO et al. (1998 a e b), concordando com TAVARES (1994) que ressaltou que a boa qualidade da água em tanques e viveiros é a chave do sucesso da produção racional da aquicultura.

Os girinos submetidos ao regime alimentar RA5, com 40, 45, 45 e $50 \%$ de PB, apresentaram diferença significativa $(\mathrm{P}<0,05)$ em relação aos outros tratamentos, sendo o maior peso médio aos 60 dias (Tabela 3). Entretanto, apresentaram o menor ganho de peso e a maior conversão alimentar aparente (Tabela 4), além de maior mortalidade $(34,3 \%)$, conforme resultados na Tabela 5. Isso indica que esse regime não se mostrou adequado para essa fase de crescimento dos girinos, de acordo com os achados de SEIXAS-FILHO et al. (2008).

Tabela 3 - Peso e comprimento médio de girinos de rã-touro alimentados com rações comerciais com diferentes teores de proteína bruta (PB) durante 60 dias

\begin{tabular}{ccccccccccc}
\hline & \multicolumn{10}{c}{ Biometrias (dias) } \\
\cline { 2 - 10 } & 0 & 15 & 30 & 45 & 60 & 0 & 15 & 30 & 45 & 60 \\
\hline & ----------- & Peso $(\mathrm{g})$ & --------- & & -------- & Comprimento $(\mathrm{mm})$ \\
RA1 & $0,033 \mathrm{a}$ & $0,39 \mathrm{a}$ & $2,00 \mathrm{a}$ & $6,22 \mathrm{~b}$ & $11,31 \mathrm{ab}$ & $5,4 \mathrm{a}$ & $11,3 \mathrm{a}$ & $20,3 \mathrm{~b}$ & $31,4 \mathrm{ab}$ & $41,2 \mathrm{a}$ \\
RA2 & $0,032 \mathrm{a}$ & $0,57 \mathrm{a}$ & $2,49 \mathrm{a}$ & $6,32 \mathrm{~b}$ & $11,72 \mathrm{ab}$ & $5,5 \mathrm{a}$ & $12,7 \mathrm{a}$ & $20,9 \mathrm{ab}$ & $30,9 \mathrm{ab}$ & $40,7 \mathrm{a}$ \\
RA3 & $0,032 \mathrm{a}$ & $0,55 \mathrm{a}$ & $2,23 \mathrm{a}$ & $5,65 \mathrm{~b}$ & $10,76 \mathrm{~b}$ & $5,3 \mathrm{a}$ & $12,8 \mathrm{a}$ & $22,4 \mathrm{ab}$ & $30,4 \mathrm{~b}$ & $39,8 \mathrm{a}$ \\
RA4 & $0,033 \mathrm{a}$ & $0,74 \mathrm{a}$ & $2,75 \mathrm{a}$ & $7,83 \mathrm{a}$ & $12,54 \mathrm{ab}$ & $5,5 \mathrm{a}$ & $13,8 \mathrm{a}$ & $22,9 \mathrm{ab}$ & $33,3 \mathrm{ab}$ & $41,3 \mathrm{a}$ \\
RA5 & $0,033 \mathrm{a}$ & $0,73 \mathrm{a}$ & $3,81 \mathrm{a}$ & $8,91 \mathrm{a}$ & $13,17 \mathrm{a}$ & $5,6 \mathrm{a}$ & $14,2 \mathrm{a}$ & $24,3 \mathrm{a}$ & $34,9 \mathrm{a}$ & $42,1 \mathrm{a}$ \\
\hline
\end{tabular}

Em cada biometria, médias seguidas de pelo menos uma mesma letra não diferem entre si pelo teste de Newman-Keuls (P>0,05).

${ }^{1}$ RA1 - 22, 28, 32 e 36\% de PB); RA2 - 28, 32, 36 e 40\% de PB; RA3 - 32, 36, 40 e 45\% de PB; RA4 - 36, 40, 45 e $45 \%$ de PB; RA5 - 40, 45, 45 e $55 \%$ de PB ministrados a cada 15 dias.

Os demais regimes não apresentaram diferenças significativas entre si $(\mathrm{P}>0,05)$ quanto ao comprimento, ganho de peso e conversão alimentar aparente aos 60 dias, indicando que, em relação a esses parâmetros, qualquer um deles poderia ser indicado para o manejo dos animais.

Por outro lado, o regime RA1, com 22, 28,
32 e $36 \%$ de $\mathrm{PB}$, apresentou conversão alimentar aparente maior que os demais, nos primeiros 15 dias de experimentação. Devido a isso, esse regime não é recomendado, uma vez que demonstrou, apesar do baixo nível proteico, a necessidade de utilização de uma quantidade maior de ração para atingir ganho de peso semelhante 
aos animais alimentados com os demais regimes, apresentando um pior índice de eficiência alimentar (IEA), que é o ganho de peso médio por animal no lote, dividido pelo consumo médio de ração por girino. Isso implica aumento de custos operacionais da criação, além de uma possível alteração funcional do fígado, conforme relatado por HIPOLITO et al. (2001) .

Segundo LIMA \& AGOSTINHO (1992), o custo com a alimentação de rãs representa $57 \%$ do custo total da criação. Dessa forma, os regimes RA2 e RA3, com $28 ; 32 ; 36$ e $40 \%$ de PB e 32; 36; 40 e $45 \%$ de $\mathrm{PB}$, respectivamente, parecem os mais adequados a esse tipo de manejo, com menor custo operacional, uma vez que o RA3 e o RA4 (com 36, 40, 45 e 45\% de $\mathrm{PB}$ ) não apresentaram diferença significativa $(\mathrm{P}>0,05)$ entre si.

Tabela 4 - Ganho de peso e conversão alimentar aparente média de girinos de rã-touro alimentados com rações comerciais com diferentes teores de proteína bruta $(\mathrm{PB})$ durante 60 dias

\begin{tabular}{|c|c|c|c|c|c|c|c|c|}
\hline & \multicolumn{8}{|c|}{ Períodos (dias) } \\
\hline & $0-15$ & $15-30$ & $30-45$ & $45-60$ & $0-15$ & $15-30$ & $30-45$ & $45-60$ \\
\hline & \multicolumn{4}{|c|}{ Ganho de Peso (g) } & \multicolumn{4}{|c|}{ Conversão alimentar aparente } \\
\hline RA1 & $0,359 \mathrm{a}$ & $1,566 \mathrm{~b}$ & $4,216 \mathrm{ab}$ & $4,816 \mathrm{a}$ & $4,57 \mathrm{a}$ & $2,06 \mathrm{a}$ & $1,04 \mathrm{a}$ & $1,89 \mathrm{~b}$ \\
\hline RA2 & $0,535 \mathrm{a}$ & $1,837 \mathrm{~b}$ & $3,776 \mathrm{~b}$ & $5,088 \mathrm{a}$ & $3,01 \mathrm{~b}$ & $1,89 \mathrm{a}$ & $1,26 \mathrm{a}$ & $1,87 \mathrm{~b}$ \\
\hline RA3 & $0,520 \mathrm{a}$ & $1,644 \mathrm{~b}$ & $3,314 \mathrm{~b}$ & $4,869 \mathrm{a}$ & $3,11 \mathrm{~b}$ & $1,83 \mathrm{a}$ & $1,18 \mathrm{a}$ & $1,88 \mathrm{~b}$ \\
\hline RA4 & $0,704 \mathrm{a}$ & $1,905 \mathrm{ab}$ & $5,073 \mathrm{a}$ & $4,451 \mathrm{a}$ & $2,40 \mathrm{~b}$ & $1,87 \mathrm{a}$ & $0,92 \mathrm{a}$ & $2,13 \mathrm{~b}$ \\
\hline RA5 & $0,692 \mathrm{a}$ & $2,901 \mathrm{a}$ & $5,024 \mathrm{a}$ & $3,361 \mathrm{~b}$ & $2,80 \mathrm{~b}$ & $1,54 \mathrm{a}$ & $1,19 \mathrm{a}$ & $3,72 \mathrm{a}$ \\
\hline
\end{tabular}

Vale ressaltar que, em todos os regimes, o peso e o comprimento médio dos animais aumentaram expressivamente em relação aos manejos feitos com um único nível de $\mathrm{PB}$ encontrados na literatura (SEIXAS FILHO, 1998a e b; ALBINATI, 2000; BARBOSA et al., 2005). Esses resultados permitem inferir uma possível relação entre os níveis de nitrogênio e o metabolismo inicial dos girinos, conforme relatado por SEIXAS FILHO et al. (2008), que observaram, pela primeira vez, somente no $25^{\circ}$ dia após o início da alimentação exógena, a presença de células hepáticas, que se encontravam com arranjo glandular mais compacto, e a formação dos acinos pancreáticos, sugerindo funcionalidade.
Não se recomenda a utilização do RA1 (22, $28,32,36 \%$ PB) por apresentar pior conversão alimentar aparente para os primeiros quinze dias, podendo comprometer financeiramente $o$ empreendimento e fisiologicamente os animais nesse período de girinagem. Nas condições deste experimento, recomenda-se o uso dos regimes RA2 $(28,32,36$ e $40 \%$ de PB) e RA3 $(32,36,40$ e $45 \%$ de $\mathrm{PB}$ ) pelo desempenho dos girinos e pelo menor custo operacional. Essas informações poderão nortear novos experimentos, melhorar as condições de cultivo, valorizar a atividade no sentido econômico, assim como aumentar o número de animais destinados à engorda.

Tabela 5 - Sobrevivência de girinos de rã-touro alimentados com diferentes regimes alimentares durante 60 dias

\begin{tabular}{lccccc}
\hline Regime & \multicolumn{5}{c}{ Biometrias (dias) } \\
\cline { 2 - 6 } alimentar & 0 & 15 & 30 & 45 & 60 \\
\hline RA1 & 100 & 100 & 90,48 & 90,48 & 86,67 \\
RA2 & 100 & 100 & 86,67 & 84,76 & 80,95 \\
RA3 & 100 & 100 & 93,33 & 90,48 & 86,67 \\
RA4 & 100 & 100 & 86,67 & 86,67 & 83,81 \\
RA5 & 100 & 87,62 & 73,33 & 71,43 & 65,71 \\
\hline
\end{tabular}

${ }^{1}$ RA1 - 22, 28, 32 e 36\% de PB); RA2 - 28, 32, 36 e 40\% de PB; RA3 - 32, 36, 40 e 45\% de PB; RA4 - 36, 40, 45 e $45 \%$ de PB; RA5 - 40, 45, 45 e $55 \%$ de PB ministrados a cada 15 dias. 


\section{CONCLUSÃO}

Pode se observar através deste trabalho que os regimes alimentares com 28, 32, 36 e $40 \%$ de PB e com 32, 36, 40 e $45 \%$ de PB foram mais adequados a esse tipo de manejo.

\section{REFERÊNCIAS}

ALBINATI, R. C. B.; LIMA, S. L.; TAFURI, M. L.; DONZELE, J. L. Digestibilidade aparente de dois alimentos protéicos e três energéticos para girinos de rãtouro (Rana catesbeiana Shaw, 1802). Revista Brasileira de Zootecnia, v.29, n.6, p.2151-2156. 2000.

ARRUDA SOARES, H.; FONTANELLO, D.; MANDELLI JR., J. Efeito da densidade de população no ganho de peso de girinos da rã-touro (Rana catesbeiana Shaw, 1802). Boletim Instituto de Pesca, v.10, p.47-51. 1983

BARBOSA, J. M.; SILVEIRA, A. M. GOMIDE, C. A. Crescimento heterogêneo de girinos de rã-touro alimentados com diferentes rações. Pesquisa Agropecuária Brasileira, v. 40. n. 10, p 1015-1019. 2005.

CASTAGnOLli, N. 1992. Piscicultura de água doce.Jaboticabal: FUNEP. 192p.

FONTANELLO, D.; ARRUDA SOARES, H.; MANDELLI JR., J.; REIS, J. M. Crescimento de girinos de Rana catesbeiana, SHAW, 1802 (rã-touro) criadas com rações de diferentes níveis protéicos. Boletim do Instituto de Pesca, 9 (único), p.125-129. 1982.

FROST, D.R.; GRANT, T.; FAIVOVICH, J.; BAIN, R.H.; HAAS, A.; HADDAD, C.F.B.; DE SÁ, R.O.; CHANNING, A.; WILKINSON, M.; DONNELLAN, S.C.; RAXWORTHY, C.J.; CAMPBELL, J.A.; BLOTTO, B.L.; MOLER, P.; DREWES, R.C.; NUSSBAUM, R.A.;
LYNCH, J.D.; GREEN, D.M.; WHEELER, W.C. The Amphibian Tree of Life. Bulletin of the American Museum of Natural History v. 297, p.1- 370, 2006.

GOSNER, K.L. A simplified table for staging anuran embryos and larvae with notes on identification. Herpetologica, v.16, p.183-190. 1960.

HIPOLITO , M.; LEME, M. C. M.; BACH, E. E. Lesões anátomo-histopatológicas em rãs-touro (Rana catesbeiana Shaw, 1802) associadas à deterioração da ração. Arquivos do Instituto Biológico, São Paulo, v. 68, n. 1, p. 111-114. 2001.

LiMA, S.L.; AGOSTINHO, C.A. A Tecnologia de Criação de Rãs. Viçosa-MG: UFV, 1992, 168p.

SEIXAS FILHO, J. T., HIPÓLITO, M., CARVALHO, V. F., FONSECA, A. M. C. R. P. M., SILVA, L. N, CASTAGNA, A. A. Alterações histopatológicas em girinos de rã-touro alimentados com rações comerciais de diferentes níveis protéicos. Revista Brasileira de Zootecnia, v.37, n.12, p.2085-2089, 2008.

SEIXAS FILHO, J. T., NAVARRO, R. D., SILVA, L. N., SOUZA, L. N. Alimentação de girinos de rã-touro com diferentes níveis de proteína bruta, Ciência Animal Brasileira, v.1 2, n.2, p. 250-256, 2011 a.

SEIXAS FILHO, J.T., OLIVEIRA, M.G.A., NAVARRO, R.D., GARCIA, S.L.R., MOURA,G. DE S.B E RIBEIRO FILHO, O.P. Atividades enzimáticas de girinos de rãtouro submetidos a rações com níveis de proteína. Archivos de Zootecnia, v. 60, n. 232, p. 1161-1170, 2011b.

SERVIÇO DE APOIO ÀS MICRO E PEQUENAS EMPRESAS DO RIO DE JANEIRO - SEBRAE-RJ. 2002. Diagnóstico da Cadeia Aqüícola Para o Desenvolvimento da Atividade no Estado do Rio de Janeiro. Rio de Janeiro-RJ. 233p. 2002.

TAVARES, L.H.S. Limnologia aplicada à aquicultura. Jaboticabal: FUNEP, 1994. 70p.

Protocolado em: 24 out. 2011. Aceito em 15 out. 2012. 